\title{
Implementasi Etika Bisnis Islam Pelaku Usaha Mikro : Studi Kasus Pada Pelaku Usaha Mikro Syariah Puspa Bank Indonesia Wilayah Jawa Barat Di Bandung Tahun 2017
}

\author{
Juliana $^{1}$, M. Faathir \& M.A. Sulthan \\ Universitas Pendidikan Indonesia \\ Julian@upi.edu
}

\begin{abstract}
This research is based on the phenomena of problems that exist in MSMEs including poor administration, low product competitiveness, low human resources, lack of mastery of science, quality of service and use of quality goods (Halal \& Thayyib). The purpose of this study was to measure the level of implementation of Islamic Business Ethics for MSME players in the PUSPA Bank Indonesia program in West Java in Bandung in 2017. The research method used was quantitative descriptive with data analysis techniques using descriptive statistics. The number of research samples is 50 consumers from 4 MSMEs engaged in the culinary, service, fashion and craft sectors. The results of the study show that the level of implementation of Islamic Business Ethics of micro business actors guided by the PUSPA program in Bank Indonesia in West Java in 2017 was very good. This can be seen from several dimensions used, namely honesty, the use of good quality goods, Ihsan, Building good relations with Consumers and Ethics sets the price of an average value of 5.8 which means very good.
\end{abstract}

\section{ABSTRAK}

Abstrak : Penelitian ini didasarkan adanya fenomena permasalahan yang ada pada UMKM diantaranya administrasi yang buruk, rendahnya daya saing produk, sumber daya manusia yang rendah, minimnya penguasaan ilmu pengetahuan, kualitas pelayanan dan penggunaan barang yang berkualitas (Halal \& Thayyib). Tujuan dari penelitian ini untuk mengukur tingkat Implementasi Etika Bisnis Islam para pelaku UMKM program PUSPA Bank Indonesia wilayah Jawa Barat di Kota Bandung pada tahun 2017. Metode penelitian yang digunakan adalah deskriptif kuantitatif dengan teknik analisis data menggunakan statistika deskriptif. Adapun jumlah sampel penelitian berjumlah 50 orang konsumen dari 4 UMKM yang bergerak pada sektor kuliner, jasa, fashion dan kerajinan. Hasil penelitian menunjukkan tingkat implementasi Etika Bisnis Islam pelaku usaha mikro binaan program PUSPA Bank Indonesia wilayah Jawa Barat tahun 2017 masuk dalam kriteria sangat baik. Ini terlihat dari beberapa dimensi yang digunakan yaitu jujur, penggunaan barang berkualitas baik, Ihsan, Membangun hubungan baik dengan Konsumen dan Etika menetapkan harga nilai rata rata nilai 5,8 yang berarrti sangat baik.

\author{
Kata kunci: \\ Etika Bisnis Islam, \\ Pelaku usaha mikro, \\ PUSPA Bank Indonesia \\ wilayah Jawa Barat
}

ARTICLE INFO: Article history: Received 15 April 2019 Revised 15 April 2019 Accepted 15 April 2019 Available online 30 May 2019

\section{Keywords:}

Islamic Business Ethics, Micro business actors, PUSPA Bank Indonesia in West Java 


\section{PENDAHULUAN}

Jumlah wirausaha di Indonesia tercatat masih di angka $0,43 \%$ dari total penduduk usia produktif, angka ini sangat jauh tertinggal dengan negara tetangga, seperti Singapura yang jumlah wirausahanya sudah mencapai 7\%, Malaysia 5\%, dan Thailand 3\% (Liliyah, 2015). Sedangkan menurut ketua KPPU mengatakan bahwa pada tahun 2017 jumlah wirausaha di Indonesia berkisar 1,6\% - 1,8\% dari jumlah penduduk di Indonesia (Republika, 2017).

Jumlah ini masih sangat jauh dari standar negara maju dengan jumlah wirausaha minimal $2 \%$ dari total usia produktif, untuk mengatasinya pemerintah berupaya menciptakan 20.000 wirausaha baru serta pengembangan 1.200 sentra industri Kecil menengah atau bisa di sebut IKM (Medistiara, 2016).

Disamping itu, perlu juga pemerintah untuk memperbaiki permasalahan industri kecil dan usaha kecil yang sudah berjalan agar terlepas dari berbagai permasalahan yang masih di alami terus menerus oleh para pelaku UMKM.

Permasalahan UMKM yang dialami terus menerus menurut Sudaryanto (2013) adalah terbatasnya modal kerja, daya saing produk, sumber daya manusia yang rendah, dan minimnya penguasaan ilmu pengetahuan serta teknologi. Permasalahan selanjutnya adalah kualitas pelayanan dan penggunaan barang yang berkualitas (halal dan thayyib).

Permasalahan tersebut merupakan akibat dari pelaku UMKM yang belum menerapkan etika bisnis islam dengan sangat baik, etika bisnis islam tidak hanya berbicara tentang nilai dan moral, lebih dari itu etika bisnis islam yang bersumber pada Al-Qur'an dan hadist yang mengatur secara teknis dan aplikatif.

Pada tahun 2015 Bank Indonesia Wilayah Jawa Barat wilayah Jawa Barat mengeluarkan Program inovatif berupa pendampingan UMKM berbasis syariah yang diberi nama PUSPA (Pendampingan UMKM Syariah Praktisi dan Akademisi). Program PUSPA BI memberikan pendampingan meliputi beberapa aspek diantaranya aspek penanaman nilai-nilai syariah, pengembangan varian dan inovasi produk, serta peningkatan kualitas produk dan kemasan. Demikian pula halnya pada aspek pemasaran dan pembukuan keuangan (Sidik, 2016). Program ini tentunya akan berdampak pada penyelesaian permasalahan yang sering terjadi pada UMKM.

Adapun tujuan dari penelitian ini adalah untuk mengukur tingkat Implementasi Etika Bisnis Islam pada pelaku UMKM yang telah mengikuti program pendampingan pada tahun 2017, sampel penelitian ini berjumlah 4 UMKM yang bergerak pada sektor jasa, makanan dan kerajinan serta 50 orang konsumen dari 4 UMKM yang diteliti.

Muhammad Jibril Sobron dkk (2017) melakukan penelitian terkait Efectiveness of Sharia SMEs Assistance By Goverment, Zakat Institution And Academics In Bandung, Indonesia yang bertujuan untuk mengukur tingkat efektivitas program pendampingan PUSPA Bank Indonesia Wilayah Jawa Barat dengan salah satu parameter keberhasilan program PUSPA adalah syariah compliance yang terdiri dari membuat akun Bank Syariah, mengetahui Fiqh Muamalah, implementasi etika bisnis islam dan menggunakan bahan yang halal dan Thayyib, indikator Syariah Complience mendapat nilai rata-rata $56 \%$ dengan kriteria sangat bagus.

Adapun hasil penelitian Juliana dan Habibah (2017) yang meneliti Sharia Complience dan etika bisnis islam sentra usaha peci cianjur adalah adanya pusat pendidikan keagamaan atau pesantren berdampak pada tingkat penerapan etika bisnis islam, sama halnya dengan program PUSPA yang bekerjasama dengan Misykat DPU Daarut Tauhid dalam 
pembinaan kerohanian para pelaku UMKM yang termasuk dalam anggota.

\section{KAJIAN PUSTAKA}

\section{Bisnis Islam}

Definisi bisnis secara umum dikemukakan oleh Alma (2013) dalam bukunya menyatakan bisnis adalah sejumlah total usaha yang meliputi pertanian, produksi, konstruksi, distribusi, transportasi, komunikasi, usaha jasa dan pemerintah, yang bergerak dalam bidang membuat dan memasarkan barang dan jasa kepada konsumen.

Sementara definisi Bisnis Islam dikemukakan oleh yusanto (2002) dalam bukunya bahwa Bisnis Islam adalah serangkaian aktivitas Bisnis dalam berbagai bentuknya yang tidak dibatasi jumlah kepemilikan hartanya termasuk profit, namun dibatasi dalam cara memperolehnya dan pendayagunaan hartanya karena aturan halal dan haram.

Dari pengertian tersebut dapat disimpulkan bahwa bisnis merupakan suatu kegiatan yang melakukan jual beli antara produsen dengan konsumen terhadap barang dan jasa, dimana tidak ada batasan dalam meraih keuntungan dan manfaat namun di atur bagaimana cara memperolehnya dalam ajaran Al-Qur'an, As-Sunnah, Al-Ijma dan Qiyas (Ijtihad).

Adapun prinsip berbisnis yang dicontohkan oleh Rasulullah SAW, yang dikutip dari Norvadewi (2015) dalam jurnalnya yaitu, prinsip pertama adalah Customer Oriented yaitu prinsip Bisnis yang selalu menjaga kepuasan pelanggan (Afzalurrahman, 1997), Kedua adalah Transparansi mengenai mutu, kuantitas, komposisi, unsur-unsur kimia dan lain-lain agar menimbulkan rasa aman dan nyaman bagi konsumen.
Prinsip Ketiga adalah Persaingan yang Sehat dengan cara saling memberikan pelayanan terbaik, inovasi produk dan tidak adanya praktek kolusi, Keempat Keadilan kepada konsumen dengan tidak melakukan penipuan dan memberikan pelayanan yang sama kepada seluruh konsumen.

\section{Etika Bisnis Islam}

Kata Etika berasal dari bahasa latin 'etos' yang berarti 'kebiasaan'. Sinonimnya adalah 'moral', juga berasal dari bahasa yang sama 'mores' yang berarti 'kebiasaan'. Sedangkan bahasa arabnya 'akhlak', bentuk jamak dari mufradnya 'khuluq' artinya 'budi pekerti'. Keduanya bisa diartikan sebagai kebiasaan atau adat istiadat (custom atau mores), yang menunjuk kepada perilaku manusia itu sendiri, tindakan atau sikap yang dianggap benar atau baik (Hasan, 2009).

Adapun faktor yang mengambarkan tindakan etis bersandar pada faktor intrepetasi hukum, faktor-faktor organisasional, dan faktor individual yang meliputi tahap perkembangan moral, nilai pribadi dan personalitas, Gambaran keluarga, Gambaran teman sebaya, pengalaman hidup, dan faktor situasional (Badroen, 2006).

Etika dibagi menjadi dua teori dasar yaitu Etika Teologi dan Etika deontologi. Etika teologi menilai suatu tindakan itu baik atau buruk dari sudut tujuan, hasil sasaran, atau keadaan optimum yang dapat dicapai (Keraf, 1998). Sedangkan etika deontologi menurut Keraf (1998) adalah bahwa suatu tindakan itu baik bukan dinilai dan dibenarkan berdasarkan akibat atau tujuan baik dari tindakan tersebut, melainkan berdasarkan tindakan itu sendiri.

Menurut ernani Etika Bisnis adalah aturan main prinsip dalam organisasi yang menjadi pedoman membuat keputusan dan tingkah laku (Hadiyati, 2009).

Definisi etika bisnis islam menurut Djakfar adalah norma-norma Etika yang berbasiskan al-Qur'an dan Hadits yang harus 
dijadikan acuan oleh siapapun dalam aktivitas Bisnis (Djakfar, 2012, hal. 29). Dengan begitu Etika Bisnis Islam termasuk dalam Etika Theologis, yang menjadi ukuran Etika theologis adalah baik buruknya perbuatan manusia didasarkan atas ajaran Tuhan (Yaqub, 1985).

Adapun prinsip Etika Bisnis Islam menurut Djakfar (2012, hal. 34-41) diantaranya jujur, menjual barang yang baik mutunya, dilarang menggunakan sumpah, longgar dan bermurah hati, membangun hubungan baik antar Konsumen, tertib administrasi dan Etika menetapkan harga.

Sedangkan menurut Al-khateeb (2000) dalam jurnalnya menyebutkan prinsip-prinsip Etika Bisnis Islam yang tidak lepas dari nilainilai At-taqwa, As-Sidq, Al-Amanah, AlIhsan, Al-Istiqamah, An-nasihah, At-tasamuh, dan Al-I'tida, sedangkan Syed Nawab Haidar Naqvi dalam buku "Etika dan Ilmu Ekonomi : Suatu Sintesis Islami" menyatakan bahwa etika bisnis islam tidak terlepas dari empat aksiomia etika ekonomi yang terdiri dari tauhid, keseimbangan (keadilan), kebebasan dan tanggung jawab (Nawatmi, 2010).

Nawatmi (2010) dalam jurnalnya menjelaskan lima prinsip etika bisnis dalam islam yang tidak jauh berbeda dengan yang disampaikan oleh Syed Nawab Haidar Naqvi, diantaranya prinsip tersebut adalah Kesatuan, Keseimbangan, keadilan, kebebasan berkehendak, Tanggung Jawab dan Kebenaran.

\section{Dimensi dan Indikator Implementasi Etika Bisnis Islam}

Dalam penelitian ini, indikator yang digunakan dalam mengukur implementasi etika bisnis Islam di sesuaikan oleh objek penelitian yang di gunakan yaitu Konsumen dari pelaku UMKM, dapat di simpukan bahwa indikator Implementasi etika bisnis Islam adalah:
1. Jujur : Menjelaskan kondisi barang/jasa, Barang /jasa sesuai dengan kuantitas dan kualitas

2. Penggunaan barang berkualitas baik : Penjelasan asal-usul barang

3. Ihsan : Keramahan terhadap konsumen dan Penggunaan bahasa yang sopan

4. Membangun hubungan baik dengan Konsumen : Perhatian pada konsumen dan Adanya akses komunikasi bagi konsumen.

5. Etika menetapkan harga : Terdapat daftar harga dan Harga yang proporsional.

\section{METODE PENELITIAN}

Metode yang di gunakan adalah Metode deskriptif yang merupakan upaya untuk memperoleh deskripsi yang lengkap dan akurat dari suatu situasi (Kuncoro, 2011, hal. 17). Adapun berkenaan dengan model statistik yang digunakan yaitu statistik deskriptif dengan menyajikan data dalam bentuk tabel dan grafik; kedua, meringkas dan menjelaskan distribusi data dalam bentuk tendensi sentral, variasi dan bentuk (Santoso, 2000).

Teknik penarikan sampel yang digunakan yaitu Nonprobabilty sampling dimana elemen yang dipilih atas dasar availabilitasnya atau karena pertimbangan pribadi peneliti bahwa mereka dapat mewakili populasi (Ferdinand, 2014, hal. 176), dan teknik sampling yang digunakan adalah Convenience karena untuk mempermudah peneliti untuk memberikan penilaian terhadap implementasi etika bisnis islam dengan cara mencari konsumen yang bersedia diminta tanggapannya.

Dalam penelitian ini sampel yang di teliti adalah 50 orang konsumen dari 4 UMKM binaan Program PUSPA tahun 2017 yang mewakili beberapa bidang usaha yaitu; UMKM dari sektor kuliner, fashion, jasa dan kerajinan.

Adapun bobot penilaian hasil 
pengelolaan data penilaian adalah sebagai berikut :

Tabel 1. Bobot Pengelolaan Data Observasi

\begin{tabular}{lcc}
\hline No & Rentang & Penafsiran \\
\hline 1. & $1-2,5$ & Kurang Baik \\
2. & $2,6-4$ & Cukup Baik \\
3. & $4,1-5,5$ & Baik \\
4. & $5,6-7$ & Sangat Baik \\
\hline
\end{tabular}

Sumber : Ferdinand (2014)

\section{HASIL DAN PEMBAHASAN}

Program pendampingan PUSPA pada tahun 2017 telah mendampingi 23 UMKM yang berdomisili di Bandung dan sekitarnya, usaha mikro yang di dampingi dalam program PUSPA terdiri dari beberapa bidang usaha yaitu jasa, kuliner, dan kerajinan. Dalam penelitian ini diambil empat pelaku usaha mikro dari masing-masing bidang usaha, berikut ini tabel sebaran objek penelitian:

Tabel 1 .Sebaran Usaha Mikro

\begin{tabular}{|c|c|c|}
\hline $\begin{array}{l}\text { Bidang } \\
\text { Usaha } \\
\end{array}$ & Nama Usaha & Owner \\
\hline Jasa & $\begin{array}{c}\text { Diff } \\
\text { Reflexiology }\end{array}$ & Dudu Hafidz \\
\hline Jasa & Penjahit Wahyu & $\begin{array}{c}\text { Beti Sri Kartini } \\
\text { \&Yuyu } \\
\text { Wahyudin }\end{array}$ \\
\hline Kuliner & $\begin{array}{c}\text { Warung Opi } \\
\text { Kumis }\end{array}$ & Enih Pidiah \\
\hline Kerajinan & Flanelyn & Rini Rochaeni \\
\hline
\end{tabular}

Berdasarkan rekapitulasi hasil penelitian, maka diperoleh hasil tingkat implementasi etika bisnis islam oleh pelaku UMKM yang masuk dalam kategori sangat baik dengan nilai rata-rata 5,8. Berikut ini adalah hasil penilaian setiap dimensi yang dinilai:

\begin{tabular}{l|c}
\hline \multicolumn{1}{c|}{ Indikator } & Hasil \\
\hline Menjelaskan kondisi barang/jasa & 5,4 \\
Barang/jasa sesuai dengan kuantitas & 6,0
\end{tabular}

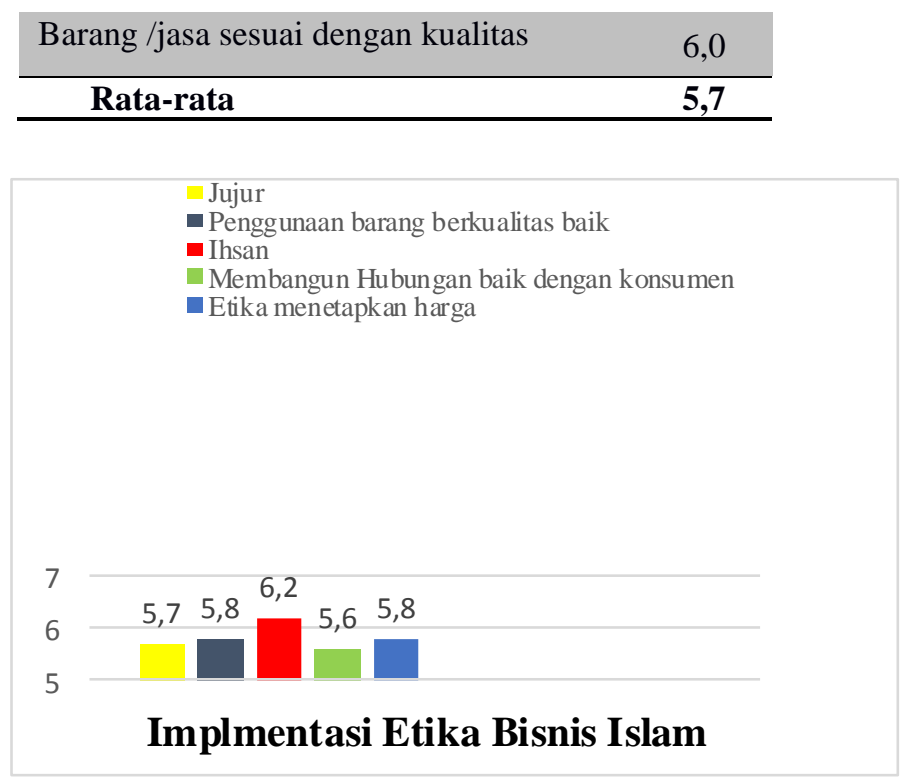

Gambar 1. Implementasi Etika Bisnis Islam

\section{Jujur}

Hasil penelitian implementasi dimensi jujur maka diperoleh hasil implementasi kejujuran adalah 5,7 yang termasuk dalam kriteria sangat baik, berikut rinciannya :

Tabel 2. Implementasi Dimensi Kejujuran

Salah satu pelaku UMKM yaitu UMKM Diff' Reflexiology selalu menjelaskan kondisi pelayanan jasa bagi konsumen, mencatat dan memastikan waktu pemakaian jasa serta memastikan bahwa pelayanan sesuai dengan permintaan konsumen.

Hasil penelitian ini sejalan dengan penelitian Heri Irawan (2017) menyatakan bahwa aspek kejujuran Pedagang sembako di pasar Sinjai diukur dari transparansi hasil timbangan dan ketepatan timbangan, masingmasing poinnya mendapatkan hasil $95 \%$ untuk transparansi dan $90 \%$ ketepatan timbangan.

\section{Penggunaan barang berkualitas baik}

Berdasarkan rekapitulasi hasil penelitian pada 50 orang konsumen, diperoleh hasil implementasi dimensi sebagai berikut:

Tabel 3. Implementasi Dimensi Penggunaan barang berkualitas baik 
Dimensi penggunaan barang berkualitas baik dengan indikator penjelasan asal-usul barang masuk dalam kriteria Sangat Baik dengan nilai rata-rata 5,8.

\begin{tabular}{cc}
\hline Indikator & Hasil \\
\hline Keramahan terhadap konsumen & 6,1 \\
Penggunaan bahasa yang sopan & 6,3 \\
\hline Rata-rata & $\mathbf{6 , 2}$ \\
\hline
\end{tabular}

Fakta lapangan menyatakan hanya 1 UMKM yang diteliti memiliki legalisasi terkait usaha dan sertifikat keterampilan, 3

UMKM lainnya belum memiliki ijin terkait legalitas halal, PIRT, sertifikat keterampilan dan ijin usaha. Tetapi UMKM tersebut selalu memastikan kepada setiap konsumennya jika bahan yang di gunakan serta jasa yang diberikan selalu memperhatikan aspek keamanan, kenyamanan dan kehalalan.

Ihsan

Hasil penelitian terkait tingkat implementasi dimensi Ihsan adalah sebagai berikut;

Tabel 4. Implementasi Dimensi Ihsan

\begin{tabular}{lc}
\hline Indikator & Hasil \\
\hline Keramahan terhadap konsumen & 6,1 \\
Penggunaan bahasa yang sopan & 6,3 \\
\hline Rata-rata & $\mathbf{6 , 2}$ \\
\hline
\end{tabular}

Hasil penelitian terhadap dimensi Ihsan masuk dalam kriteria sangat baik dengan nilai rata-rata 6,2. Sejalan dengan penelitian Elida Elfi Barus dan Nuriani (2017) menyatakan bahwa tanggapan konsumen terhadap pelayanan yang dilakukan oleh para karyawan Rumah makan Wong Solo di Medan sangat baik, konsumen berpendapat bahwa para karyawan selalu menggunakan bahasa yang sopan dan sikap yang ramah dalam melayani konsumen.

\section{Membangun Hubungan Baik dengan Konsumen}

Berdasarkan rekapitulasi hasil penelitian, Implementasi dimensi Membangun hubungan baik dengan konsumen, maka diperoleh hasil penelitian sebagai berikut:

Tabel 5. Implementasi Dimensi Membangun Hubungan Baik dengan Konsumen

Dimensi Membangun hubungan baik dengan konsumen masuk dalam kriteria sangat baik dengan nilai 5,6. Jika dimensi ini terimplementasi sangat baik, maka akan berdampak pada peningkatan daya saing terhadap UMKM itu sendiri, melihat indikator yang digunakan adalah indikator yang digunakan oleh perusahaan besar dan ternama, namun hal ini perlu didukung oleh sumber daya manusia yang berkompeten dalam membangun Good Relation.

Sejalan dengan penelitian yang dilakukan oleh Juliana dkk (2017) yang meneliti tentang Kepatuhan Syariah untuk Meningkatkan Daya Saing Industri Hijab menyatakan bahwa $70 \%$ responden setuju jika bisnis harus memiliki sumber daya yang rajin dan berkompeten agar dapat meningkatkan daya saing.

\section{Etika menetapkan harga}

Harga yang tidak transparan bisa

\begin{tabular}{|c|c|}
\hline Indikator & Hasil \\
\hline \multicolumn{2}{|c|}{ Penjelasan asal-usul barang } \\
\hline \multicolumn{2}{|c|}{$\begin{array}{l}\text { mengandung unsur penipuan, begitu juga } \\
\text { harga yang tidak proporsional yang tidak } \\
\text { sesuai dengan kualitas yang di tawarkan akan } \\
\text { menimbulkan rasa kecewa bagi konsumen, } \\
\text { Berdasarkan hasil penelitian, Implementasi } \\
\text { dimensi Etika menetapkan harga yang } \\
\text { dilakukan oleh pelaku usaha mikro adalah } \\
\text { sebagai berikut: } \\
\text { Tabel 6. Implementasi Dimensi Etika menetapkan } \\
\text { harga }\end{array}$} \\
\hline Indikator & Hasil \\
\hline Terdapat daftar Harga & 5,3 \\
\hline Harga yang proporsional & 6,2 \\
\hline Rata-rata & 5,8 \\
\hline
\end{tabular}


Hasil penelitian dimensi Etika menetapkan harga masuk dalam kriteria sangat baik dengan nilai rata-rata 5,8 . Tersedianya daftar harga merupakan salah satu cara agar konsumen terhindar dari transaksi Gharar dan berdampak pada meningkatknya daya saing UMKM karena hal tersebut sering di terapkan oleh swalayan bahkan Hypermall.

Sedangkan Indikator harga yang proporsional sudah terimplementasikan dengan sangat baik, yang berarti harga yang di tawarkan oleh pelaku UMKM sudah sesuai dengan manfaat dan kualitas yang di tawarkan, hal ini sesuai dengan penelitian Juliana (2016) menyebutkan bahwa besar kecilnya al-Qimah tergantung pada besar kecilnya manfaat suatu barang yang menjadi patokan menetapkan nilai ekonomi suatu barang.

\section{KESIMPULAN}

Implementasi Etika Bisnis Islam masuk dalam kriteria Sangat Baik, namun dalam hal ini ada beberapa dimensi yang perlu di tingkatkan lagi meskipun dimensi tersebut masuk dalam kriteria baik, dimensi yang perlu di tingkatkan adalah tertib administrasi dan kebebasan. Adapun indikator yang mempunyai nilai terendah adalah indikator ketersediaan informasi bagi konsumen dan tersedianya sarana kritik bagi konsumen.

Permasalahan dimensi tertib administrasi adalah kurang konsistennya pelaku usaha mikro dalam mencatat berbagai hal terkait usahanya seperti mencatat pemesanan yang mempunyai manfaat agar terhindar dari kesalahan yang tidak di inginkan, hal ini di atur dalam undang-undang nomor 8 tahun 1999 pasal 4 dimana hak konsumen adalah mendapat kompensasi atas barang yang di beli apabila barang atau jasa yang diterima tidak sesuai dengan perjanjian.

Adapun tersedianya catatan keluhan konsumen yang banyak di terapkan oleh perusahaan besar dalam mengenali lebih jauh pelanggannya, dengan menggunakan fitur Big
Data yang memuat tidak hanya keluhan konsumen saja melainkan produk yang laku di pasaran, serta segmentasi konsumen yang perlu di prioritaskan, hal ini juga dapat di terapkan oleh pelaku UMKM dengan membuka sarana komplain serta mencatatnya lalu melakukan evaluasi berdasarkan catatan keluhan konsumen, hal ini akan berdampak pada hubungan antara konsumen dan pelaku usaha semakin erat karena pelaku usaha memperhatikan keinginan dari konsumennya.

Indikator tersedianya sarana kritik terhambat karena pelaku usaha kurang inisiatif untuk membuka fasilitas kritik baik secara lisan ataupun dengan cara membuat kotak kritik \& saran. Indikator terdapat daftar produk belum optimal dikarenakan Pelaku usaha belum fokus untuk menjual sesuatu yang mereka bisa dan dapat dimaksimalkan untuk membangun Brand usahanya.

\section{DAFTAR PUSTAKA}

Al-Khatib, Y., \& Al-Torkistan, H. M. (2000). The Evaluation of the Saudi Firms' Marketing Practice from Islamic point of View. Journal of King Abdulaziz University Islamic Economics, 12(1), 10. Retrieved from

https://papers.ssrn.com/sol3/papers.cfm?a bstract_id=3074258

Afzalurrahman. (1997). Muhammad Sebagai Seorang Pedagang. Jakarta: Yayasan Swarna Bhumy.

Alma, B. (2013). Manajemen Pemasaran dan Pemasaran Jasa. Bandung: Alfabeta.

Badroen, F. (2006). Etika Bisnis Islam. jakarta: kencana.

Barus, E. E., \& Nuraini. (2017, September). Implementasi Etika Bisnis Islam: Studi Pada Rumah Makan Wong Solo Medan. Jurnal Persepektif Ekonomi Darussalam, $3(1), 125$.

Djakfar, M. (2012). Etika Bisnis: Menangkap Spirit Ajaran Langit dan Pesan Moral Ajaran Bumi. Jakarta: Penebar Plus.

Ferdinand, A. (2014). Metode Penelitian Manajemen: Pedoman Penelitian untuk Penulisan Skripsi, Tesis dan Disertasi Ilmu Manajemen. Semarang: Badan Penerbit Universitas Diponegoro. 
Hadiyati, E. (2009). Pengaruh Etika Bisnis terhadap Kewirausahaan pada Usaha Kecil Bengkel Les di Pujon. Jurnal Manajemen Gajayana, Vol.6, No.1.

Hasan, A. (2009). Manajemen Bisnis Syariah. Yogyakarta: Pustaka Pelajar.

Irawan, H. (2017). Penerapan Etika bisnis Islam pada pedagang sembako di Pasar Sentral Sinjai (Thesis). Makassars: Pascasarjana UIN Alauddin Makassar.

J. Juliana, Firmansyah, Cahyaneu, A., Moslem, H., \& Taufiq, I. (2017). Shari'a Compliance to Improve the Competitiveness of the Industry of Hijab. ICEBF (p. 696). Bandung: Athlantis Press.

J. Juliana, Moslem, H., \& Sulthan, M. A. (2017). Analysis of Sharia Compliance Islamic Business The Industrial Centers of Peci Survey on Cianjur Regency Craftsme. $I C E B F$ (p. 698). Bandung: Athlantis Press.

J. Juliana, Pratama, B., \& Firmansyah. (2016, Mei). Telaah Pemikiran Ekonomi Islam : Yahya Bin Adam Al-Qarashi $( \pm 140$ H/755 M 203 H/818 M). Ekspansi, 8(1), 82.

Keraf. (1998). Etika bisnis: tuntutan dan relevansinya. Yogyakarta: Kanisius.

Kuncoro, M. (2011). Metode Kuantitatif. Yogyakarta: UPP Sekolah Tinggi Ilmu Manajemen YKPN.

Liliyah, A. (2015, maret 10). SWA. Retrieved from SWA.co.id: http://swa.co.id/swa/trends/management/j umlah-wirausaha-indonesia-hanya-043dari-total-populasi

Maharani, D. (2017). Penerapan Kejujuran Dan Tanggung Jawab Dalam Etika Bisnis Syariah Pada Wirausaha Muslim Di Kecamatan Medan Marelan. Jurnal Ilmiah Manajemen dan Bisnis, 3(2), 24.

Medistiara, Y. (2016, september 14). Detik Finance. Retrieved from finance.detik.com: https://finance.detik.com/industri/d3297697/menperin-targetkan-20000pengusaha-baru-hingga-2019

Nawatmi, S. (2010). Etika Bisnis dalam Persepektif Islam. Fokus Ekonomi (FE), 9(1), 54.

Norvadewi. (2015). Bisnis Dalam Persepektif Islam (Telaah Konsep, Prinsip dan Landasan Normatif). Al-Tijary Vol. 01, No. $01,37$.

Republika. (2017). KPPU: Pengusaha di Indonesia Hanya 1,6\% jumlah populasi. Bandung: Republika.Co.Id.
Santoso. (2000). Buku Latihan SPSS Statistik Parametrik. jakarta: PT. Elex Media Komputindo.

Sidik, F. (2016). BI Ingin Jabar Jadi Poros Pendidikan Ekonomi Syariah Di Indonesia. Bandung: Bisnis.com.

Siswanto. (2011). Tingkat Manajerial dan Pengelolaan Keuangan Usaha Mikro, Kecil dan Menengah (UMKM) di KAB. Kulonprogo. Jurnal Pendidikan Akuntansi Indonesia, 9(1), 84.

Sobron, M. J., Bakri Rangkuti, M. H., Husniati, \& Utami, S. A. (2017). Efectiveness Of Sharia SMEs Assistance By Goverment, Zakat Institution And Academics In Bandung, Indonesia. South East Asia International Islamic Philanthropy Conference (p. 315). Melaka: Uni Charity Society.

Sudaryanto, Ragimun, \& Wijayanti, R. R. (2013). Strategi Pemberdayaan UMKM Menghadapi Pasar Bebas Asean. Jurnal Kementrian Keuangan, 2.

Yaqub, H. (1985). Etika Islam: Pembinaan Akhlaqulkarimah (suatu Pengantar). Jakrta: Diponegoro.

Yusanto, I., \& Widjayakusuma, M. K. (2002). Menggagas Bisnis Islami. Jakarta: Gema Insani Press. 